\title{
Estudo da substituição do nylon por compósito de polipropileno com fibra de vidro
}

\author{
Study of replacement of nylon by \\ polypropylene composite and \\ glass fiber
}

Gilmar Cordeiro da Silva ${ }^{1}$, Geraldo Flávio Ximenes Ladeira ${ }^{1}$,
Hermano Nascimento Júnior ${ }^{1}$, José Rubens Gonçalves Carneiro ${ }^{1}$

\footnotetext{
${ }^{1}$ Pontifícia Universidade Católica de Minas Gerais - Programa de Pós-Graduação em Engenharia Mecânica - Av. Dom José Gaspar, 500 - PUCMINAS - CP: 30535910, Belo Horizonte, Minas Gerais, Brasil.

e-mail: gilmarcord@gmail.com, liderplast@liderplast.com.br, hermano.junior@hotmail.com, joserub@pucminas.br
}

\section{RESUMO}

Peças fabricadas com polímeros de alto desempenho têm sido substituídas por materiais similares, sendo produzidas com uma composição de polipropileno (PP), que tem um custo mais baixo. Uma das composições mais comumente utilizadas é a junção do polipropileno com fibras, resultando na formação de um novo material, com características diferentes às dos seus constituintes. Este tipo de junção é denominado compósito. O objetivo deste trabalho é avaliar o comportamento do compósito de polipropileno com fibra de vidro para a substituição do material da carcaça de um elemento filtrante fabricado atualmente com um compósito de nylon e fibra de vidro na proporção de $30 \%$ em peso. Foram injetados corpos de prova usando PP puro e com cargas de fibra de vidro nas proporções de $15 \%, 20 \%$ e 30\%, a análise de comportamento, através de ensaio de tração, flexão, resistência ao impacto, dureza, índice de fluidez e determinação do índice de contração indicou o compósito PP com 30\% de fibra de vidro com melhor comportamento. Posteriormente realizou-se a injeção da carcaça do elemento filtrante no compósito PP com 30\% de fibra de vidro que passou por testes práticos.

Palavras-chave: Polipropileno, nylon, fibra de vidro, elemento filtrante.

\section{ABSTRACT}

Parts made from high performance polymers have been replaced by similar materials, produced with a polypropylene (PP) composition, with a lower cost. One of the most commonly used compositions is made by the the joining of polypropylene with fibers, resulting in a new product with different characteristics from those of its constituents. This type of joint is called composite. The objective of this study is to evaluate the behavior of the fiberglass polypropylene composite for the replacement of the housing material of a filter element which is currently manufactured with a nylon and glass fiber composite in the proportion of $30 \%$ by weight. Test specimens was injected by using PP pure and as well as with 15\%, 20\% and 30\% fiberglass loads, for behavior analysis through tensile test, flexural strength, impact strength, hardness, flow index and determination of contraction rate. After the injection in the composite with best behavior, PP $30 \%$ fiberglass, the filter element housing was subjected practical tests.

Keywords: Polypropylene, fiberglass, plastic injection. filter element.

\section{INTRODUÇÃO}

Fatores como custo e facilidade na obtenção da matéria prima para a fabricação de produtos por processo de injeção plástica, são fundamentais na composição do preço final do produto.

Peças fabricadas com polímeros de alto desempenho têm sido substituídas por materiais similares. Uma das composições mais comumente utilizadas é a junção do polipropileno com fibras, resultando na formação de um novo material, com características diferentes às dos seus constituintes. Este tipo de junção é 
denominado compósito. O polipropileno (PP) é uma comoditie nacional, encontrada facilmente no mercado, vendida em lotes com menores quantidades e com precificação mais baixa e estável. Menores ciclos de produção e dispêndio de insumos devidos à baixa pressão de injeção e temperatura de plastificação em relação ao Nylon são pontos de relevância observados no PP.

Os polímeros distinguem-se entre si pelo grau da diferenciação, escala de produção, nível de consumo e assim no valor agregado. Podem então ser classificados, em três grandes grupos em polímeros para usos gerais (commodities), polímeros para usos específicos (quase-commodities) e polímeros de alto desempenho (especialidades) [1]. Os polímeros tipo commodities são aqueles produzidos em alta escala, tem baixo valor agregado, não apresentam diferenciação, são utilizados para finalidades gerais e são consumidos em grandes quantidades como exemplo o polietileno, polipropileno, poli (cloreto de vinila - PVC) e o poliestireno. Como polímeros quase-commodities pode se citar as poliamidas, ABS, SAN, poliuretano, policarbonato e o PET, que tem características especificas de plástico de engenharia e mercado bem direcionado, porém produzido em maior escala. Já entre os polímeros de alto desempenho, podem ser citados o poli (óxido de metileno) (POM - Poliacetal), poli(tetrafluoretileno) (PTFE), poli (tereftalato de butileno) (PBT), poli(sulfeto de fenileno) (PPS) e polímeros líquido-cristinalinos. São produtos específicos, com propriedades bem definidas e incomuns, tem alto valor agregado e são produzidos em escala menores. [1].

Hoje em dia, a simples observação do trânsito nas grandes metrópoles leva à constatação de que o número de veículos aumenta constantemente. Além disso, uma significativa quantidade de partes automotivas, que anteriormente eram fabricadas com materiais metálicos, é atualmente fabricada com materiais poliméricos. Na década de 70, utilizava-se cerca de $30 \mathrm{~kg}$, na década de 90 este valor chegou a $180 \mathrm{~kg}$ e estimase que chegue a $200 \mathrm{~kg}$ em veículos atuais [2] os quais cerca da metade corresponde a compostos de polipropileno (PP).

Estudos sobre a viabilidade do uso da fibra curta de sílica como agente de reforço em compósito de polipropileno homopolímero aplicada em peças internas automotivas [3] e otimização das propriedades mecânicas do polipropileno injetado e reforçado com fibras longas [4] relatam que a composição de PP e fibra de vidro podem ser amplamente utilizadas no campo industrial, especialmente em aplicações automotivas em função de suas excelentes propriedades mecânicas e baixo custo. Em porcentagem, a participação de materiais poliméricos nos veículos evoluiu de $10 \%$ a $13 \%$ do peso total do veículo em 1990 para $20 \%$ na década de 2000 [5].

O mercado atual é extremamente competitivo e qualquer redução de preço é da maior importância. No entanto, existe a necessidade de informações sobre as propriedades do material a ser utilizado na substituição do já existente de tal forma que não comprometa a qualidade final do produto.

O objetivo deste trabalho é avaliar o comportamento do compósito de polipropileno com fibra de vidro para a substituição do material da carcaça de um elemento filtrante fabricado atualmente com um compósito de nylon e fibra de vidro na proporção de $30 \%$ em peso. De forma geral, os dados obtidos neste estudo poderão ser utilizados em outras situações similares de produção servindo como base para o desenvolvimento de novas pesquisas e desenvolvimento de outros produtos.

\section{MATERIAIS E MÉTODOS}

\subsection{Matéria prima e molde de injeção}

A matéria prima é o polipropileno puro, o polipropileno com os percentuais $15 \% \%, 20 \%$ e $30 \%$ de fibra de vidro e o Nylon com $30 \%$ de fibra de vidro. Os materiais foram adquiridos da empresa Petropol polímeros em embalagem separadas de $25 \mathrm{Kg}$ cada. O molde utilizado na injeção dos corpos de prova é composto de quatro postiços intercambiáveis, sendo cada postiço composto de duas cavidades e pertencente a Pontifícia Universidade Católica de Minas Gerais.

\subsection{Injeção dos corpos de prova}

As injeções dos corpos de prova em PP puro, 15\%, 20\% e 30\% com fibra de vidro foram realizadas em uma injetora da marca Sinitron com capacidade de plastificação $201 \mathrm{~cm}^{3}$, força máxima de fechamento de 90 toneladas e sistema de extração automática.

Antes do início das injeções dos corpos de prova, todo material polimérico utilizado anteriormente dentro do funil e na rosca da injetora foi retirado para não ocorrer qualquer tipo de contaminação. Para isso, o bico de injeção da máquina injetora foi recuado e todo o material indevido foi expelido. Nas injeções dos corpos de prova para cada material foi observado o tempo de aquecimento em estufa $\left(80^{\circ} \mathrm{C}\right.$ por duas horas) 
antes da realização das injeções de acordo com as especificações do fornecedor da matéria prima.

Após a expurga, o primeiro material injetado foi o (PP 100\% virgem), para isso o material foi inserido no funil da injetora que, ainda com o bico injetor recuado, continuou a expurgar o material. Essa etapa foi realizada para que, caso ainda houvesse algum resíduo do material indevido na rosca da injetora, o mesmo fosse retirado totalizando a limpeza em tal região. Em seguida o bico injetor avançou e acoplou no bico de injeção da parte superior do molde, posteriormente ocorreu o fechamento do molde e início da produção dos corpos de prova.

As dez primeiras peças injetadas foram descartadas como uma terceira medida de segurança com o intuito de se eliminar qualquer possibilidade de contaminação do material e também para garantir a estabilidade da injetora no momento da injeção dos corpos de prova. Esse procedimento foi repetido a cada troca de composição da matéria prima. Todos os corpos de prova foram injetados em um único molde contendo duas cavidades de cada modelo em cada postiço, cada um conforme sua norma específica.

\subsection{Caracterização mecânica, química e termogravimétria}

Os ensaios de tração foram realizados em laboratório com temperatura ambiente controlada conforme norma ASTM-D638 [6] e executados em uma máquina universal de marca Instron, modelo 5867R, com distância entre garras de $115 \mathrm{~mm}$, velocidade de ensaio de $50 \mathrm{~mm} / \mathrm{min}$ e célula de carga de $30 \mathrm{kN}$. A incerteza do equipamento é de $1,5 \%$ e as propriedades mecânicas analisadas nesse ensaio foram as de limite de resistência à tração (LRT) e alongamento na ruptura.

Os ensaios de flexão foram realizados conforme norma ASTM-D790 [7] e executados na mesma máquina dos ensaios de tração, com distância entre os apoios de $50 \mathrm{~mm}$, velocidade de ensaio de $2 \mathrm{~mm} / \mathrm{min}$ e célula de carga de $30 \mathrm{kN}$. As propriedades mecânicas analisadas nesse ensaio foram a de limite de resistência à flexão (LRF) e módulo de elasticidade na flexão (MEF). A amostra foi apoiada como uma viga flexionada a um taxa constante. Durante o procedimento, a força aplicada à amostra foi mensurada.

Os ensaios de impacto (IZOD) foram realizados conforme norma ASTM-D256 [8] e executados em um equipamento universal da marca Ceast com a utilização de um martelo de 2,75J. A incerteza do equipamento é de $1,5 \%$ e a propriedade mecânica analisada nesse ensaio foi a resistência ao impacto do material.

Para a caracterização química do material injetado as amostras dos corpos de prova foram analisadas utilizando as técnicas de espectroscopia no infravermelho por Transformada de Fourier (FTIR) e calorimetria exploratória Diferencial (DSC). Os equipamentos utilizados foram o FTIRThermo Nicolet Nexus 470 e o SC2920 Modulated DSC - TA Instruments. O procedimento consistiu de Rampa em atmosfera inerte com equilíbrio em $50^{\circ} \mathrm{C}$, aquecimento de $50^{\circ} \mathrm{C}$ a $300^{\circ} \mathrm{C}$ com razão de aquecimento de $20^{\circ} \mathrm{C} / \mathrm{min}$, resfriamento de $300^{\circ} \mathrm{C}$ a $50^{\circ} \mathrm{C}$ com razão de resfriamento de $20^{\circ} \mathrm{C} / \mathrm{min}$.

O teste de Termogravimetria foi feito no equipamento Analisador termogravimétrico Hi-Res TGA 2950 Thermogravimetric Analyser - TA Instruments. Utilizou-se atmosfera inerte e equilíbrio em $50^{\circ} \mathrm{C}$, aquecimento de $50^{\circ} \mathrm{C}$ a $750^{\circ} \mathrm{C}$ com razão de aquecimento de $20^{\circ} \mathrm{C} / \mathrm{min}$; posteriormente houve a troca para atmosfera oxidante, Isoterma de $5 \mathrm{~min}$, logo após outro aquecimento de $750^{\circ} \mathrm{C}$ a $850^{\circ} \mathrm{C}$ com razão de aquecimento de $20^{\circ} \mathrm{C}$; Isoterma de $1 \mathrm{~min}$.

\subsection{Microscopia eletrônica de varredura (MEV)}

Para realização da microscopia da fratura, as regiões fraturadas dos corpos de prova dos ensaios de tração foram metalizadas com ouro. Uma amostra de cada composição de matéria prima foi verificada e em cada face, três análises foram feitas: uma na borda, e duas no núcleo com diferentes ampliações.

Para a análise da fratura dos corpos de prova dos ensaios de impacto foram analisados um corpo de prova fraturado para cada material em estudo, ou seja, o polipropileno puro, o polipropileno com os percentuais $15 \%, 20 \%$ e $30 \%$ de fibra de vidro e o Nylon com $30 \%$ de fibra de vidro. O equipamento que foi utilizado é da marca Geol, modelo IT300.

\subsection{Injeção e teste prático carcaça do elemento filtrante}

Para a injeção da carcaça do elemento filtrante no compósito em polipropileno com fibra de vidro foi utilizada uma injetora da marca Sinitron, série SYA-DT com força de fechamento de 180 toneladas e capacidade de injeção de 433 gramas em poliestireno PS. Após a injeção foram realizados testes de montagem da carcaça nos elementos filtrantes e nos disco de apoio e posteriormente testes de filtragem em bancada com equipamentos composto de fluxo de óleo com atuadores de pressão calibrados. 


\section{RESULTADOS E DISCUSSÃO}

\subsection{Resultados ensaio de tração, flexão, impacto, caracterização química e termogravimétria}

As propriedades mecânicas analisadas nesse ensaio foram o limite de resistência à tração (LRT) e o alongamento na ruptura. Também foi realizado ensaio de tração em corpo de prova em nylon com $30 \%$ de fibra de vidro (poliamida), sendo esse material utilizado atualmente na confecção da carcaça do filtro.

A Figura 1 apresenta as curvas tensão versus deformação média das amostras de PP puro, com os percentuais de fibra de vidro e Nylon com 30\% de FV. Os valores que foram adotados para a elaboração das curvas são uma média dos valores encontrados para seis corpos de prova de cada proporção de carga de fibra de vidro.

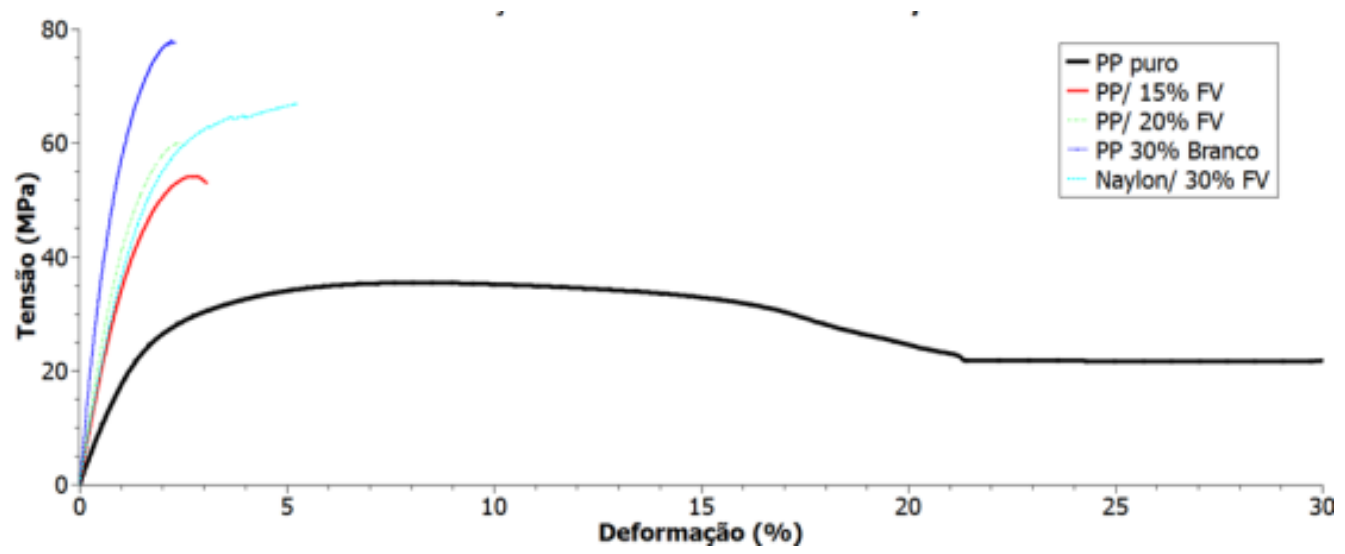

Figura 1: Curvas Tensão x deformação média PP e Nylon a $23^{\circ} \mathrm{C}-\mathrm{ASTM}$

O ensaio de tração para o PP com 0\%FV, PP15\%FV, PP20\%FV e PP30\%FV, produziu curvas de tensão x deformação distintas entre si. O PP sem carga apresentou um comportamento dúctil característico de termoplásticos, elevada deformação na ruptura com resistência à tração e módulos baixos. Nos compósitos, porém, o comportamento é frágil, com deformação linear em baixas tensões e deformação não linear em tensões maiores. Quando adicionadas as fibras ocorreu uma redução significativa no estiramento e elevado aumento no módulo. Com o aumento do teor de carga, estas características foram ainda mais acentuadas, especialmente com relação à tensão e ao módulo. Quando acrescentadas as proporções de fibra de vidro ocorreu um aumento da tensão de escoamento de 35,45 MPa no corpo de prova com PP puro para 54,15 MPa no PP com $15 \%$ de fibra de vidro. Já para os compósitos com $20 \%$ e $30 \%$ de fibra de vidro os valores das tensões de escoamento foram de $60 \mathrm{MPa}$ e $78 \mathrm{MPa}$ respectivamente, ou seja, consideráveis aumentos no valor da tensão de escoamento de $53 \%, 69 \%$ e $120 \%$ para os corpos de prova com $15 \%, 20 \%$ e $30 \%$ de fibra de vidro. Os valores encontrados assemelham se aos valores obtidos por [9].

A Figura 2 apresenta a fotografia dos corpos de prova do PP puro, 20\% FV e 30\% FV após a ruptura respectivamente.
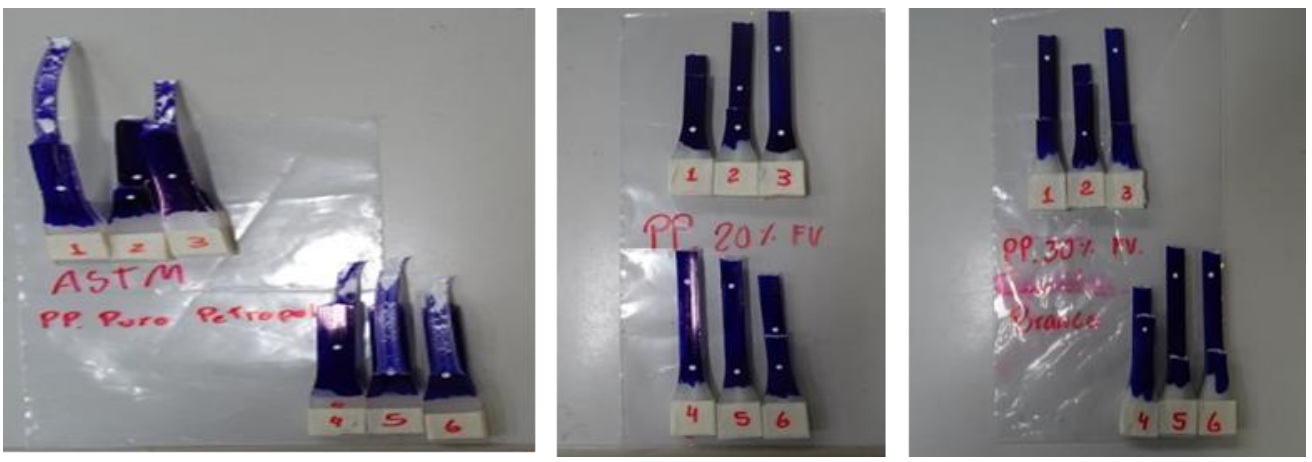

Figura 2: Corpos de prova rompidos (a) PP puro, (b) PP 20\% FV e (c) PP 30\% FV

Os ensaios de flexão foram realizados conforme a norma ASTM-D790 a temperatura ambiente $\left(23^{\circ} \mathrm{C}\right)$ 
com a umidade relativa do ar de 60\%. Observou-se que o esforço de flexão máximo necessário aumentou de acordo com o acréscimo da carga de fibra de vidro. Ocorreu variação de 46,2Mpa no material puro até 94,7Mpa no compósito com $30 \%$ de fibra de vidro. Houve aumento de $105 \%$ no esforço de flexão máximo. O módulo de Young em Mpa, também aumentou de 1,38 Gpa no material puro para 4,8 Gpa no compósito com $30 \%$ de fibra de vidro. Houve aumento de $250 \%$ no valor do módulo de Young. A fibra de vidro promoveu o aumento da rigidez do material, ou seja, a sua resistência à deformação elástica.

Os ensaios de impacto IZOD foram realizados conforme norma ASTM-D256. A influência da concentração da fibra de vidro na resistência ao impacto Izod foi determinada após o ensaio em cinco corpos de prova para cada amostra. O valor médio encontrado para o PP $15 \% \mathrm{FV}$ foi de $19,23(\mathrm{~J} / \mathrm{m})$, para o $\mathrm{PP} 20 \% \mathrm{FV}$, 47,74(J/m) e para o PP30\%FV 58,77(J/m).

A variação encontrada da resistência ao impacto com o aumento do percentual de fibras está em concordância com os relatos da literatura. [12] [13] [14]. Quanto maior o percentual de fibra, maior a resistência ao impacto das amostras testadas. Os resultados deste trabalho apontaram um aumento que variou de $148,3 \%$ a 205,6\% para o valor de resistência ao impacto $(\mathrm{J} / \mathrm{m}$ ) quando comparado ao compósito com $15 \%$ de fibra de vidro, o que está de acordo com Chiu et all [15], que mencionou um aumento significativo de resistência ao impacto com o aumento do teor de fibras em sistemas PP/FV. A presença da fibra no compósito tende a desviar a propagação da trinca no material, fazendo que ocorra um mecanismo de proteção da matriz polimérica. [10] [4].

A caracterização química dos corpos de prova injetados foi feita utilizando as técnicas de Espectroscopia no infravermelho por Transformada de Fourier (FTIR) e Calorimetria exploratória Diferencial (DSC) com Rampa em atmosfera inerte com equilíbrio em $50^{\circ} \mathrm{C}$, aquecimento de $50^{\circ} \mathrm{C}$ a $300^{\circ} \mathrm{C}$ com razão de aquecimento de $20^{\circ} \mathrm{C} / \mathrm{min}$, resfriamento de $300^{\circ} \mathrm{C}$ a $50^{\circ} \mathrm{C}$ com razão de resfriamento de $20^{\circ} \mathrm{C} / \mathrm{min}$. Os materiais foram caracterizados conforme resultados mostrados na Tabela 1. Percebe se que houve uma diminuição nos valores de energia de entalpia de cristalização e fusão quando adicionados os percentuais de fibra de vidro. As temperaturas de cristalização e fusão praticamente não variaram quando adicionados percentual de fibra de vidro.

Tabela 1: Caracterização dos corpos de prova Injetados

\begin{tabular}{l|l|l|l|l|l}
\hline \multicolumn{6}{c}{ CARACTERIZAÇÃO DOS CORPOS DE PROVA INJETADOS } \\
\hline AMOSTRA & MATERIAL & $\begin{array}{c}\text { TEMPERATURA DE } \\
\text { CRISTALIZAÇÃO }\end{array}$ & $\begin{array}{c}\text { ENTALPIA DE } \\
\text { CRISTALIZAÇÃO }\end{array}$ & $\begin{array}{c}\text { ENTALPIA } \\
\text { DE FUSÃO }\end{array}$ & $\begin{array}{c}\text { TEMPERATURA } \\
\text { DE FUSÃO }\end{array}$ \\
\hline 1 & PP- Puro & $111,31^{\circ} \mathrm{C}$ & $102,3 \mathrm{~J} / \mathrm{g}$ & $93,16 \mathrm{~J} / \mathrm{g}$ & $164^{\circ} \mathrm{C}$ \\
\hline 2 & PP- $15 \% \mathrm{FV}$ & $115,22^{\circ} \mathrm{C}$ & $84,15 \mathrm{~J} / \mathrm{g}$ & $76,11 \mathrm{~J} / \mathrm{g}$ & $162^{\circ} \mathrm{C}$ \\
\hline 3 & PP- $20 \% \mathrm{FV}$ & $114,82^{\circ} \mathrm{C}$ & $79,42 \mathrm{~J} / \mathrm{g}$ & $71,10 \mathrm{~J} / \mathrm{g}$ & $164^{\circ} \mathrm{C}$ \\
\hline 4 & PP- $30 \% \mathrm{FV}$ & $115,14^{\circ} \mathrm{C}$ & $66,36 \mathrm{~J} / \mathrm{g}$ & $60,92 \mathrm{~J} / \mathrm{g}$ & $164^{\circ} \mathrm{C}$ \\
\hline
\end{tabular}

Para o teste de Termogravimetria (TG) utilizou-se atmosfera inerte e equilíbrio em $50^{\circ} \mathrm{C}$, aquecimento de $50^{\circ} \mathrm{C}$ a $750^{\circ} \mathrm{C}$ com razão de aquecimento de $20^{\circ} \mathrm{C} / \mathrm{min}$; posteriormente houve a troca para atmosfera oxidante, Isoterma de $5 \mathrm{~min}$, logo após outro aquecimento de $750^{\circ} \mathrm{C}$ a $850^{\circ} \mathrm{C}$ com razão de aquecimento de $20^{\circ} \mathrm{C}$; Isoterma de $1 \mathrm{~min}$. A Tabela 2 mostra os resultados encontrados no teste de termogravimetria (TG) para cada amostra. Observa-se que para cada material ensaiado houve correspondência no percentual de polímero e carga inorgânica.

Tabela 2: Resultados da Termogravimetria

\begin{tabular}{l|l|l|l|l}
\hline \multicolumn{5}{c}{ RESULTADOS TERMOGRAVIMETRIA } \\
\hline AMOSTRA & MATERIAL & POLÍMERO & CARGA OXIDÁVEL & CARGA INORGÂNICA \\
1 & PP- Puro & $99 \%$ & $1 \%$ & $0 \%$ \\
2 & PP- 15\% FV & $85 \%$ & $0 \%$ & $15 \%$ \\
3 & PP- 20\% FV & $82 \%$ & $0 \%$ & $18 \%$ \\
4 & PP- 30\% FV & $72 \%$ & $0 \%$ & $28 \%$ \\
\hline
\end{tabular}




\subsection{Resultados Microscopia eletrônica de varredura na região de fratura dos corpos de prova do en- saio de tração}

Para realização da microscopia da fratura, as regiões fraturadas dos corpos de prova dos ensaios de tração foram metalizadas em uma máquina de metalização com ouro. A Figura 3 apresenta as micrografias com 250x de ampliação na região de fratura dos corpos de prova injetados em PP puro e nos compósitos com 15\% e $30 \%$ de fibra de vidro.
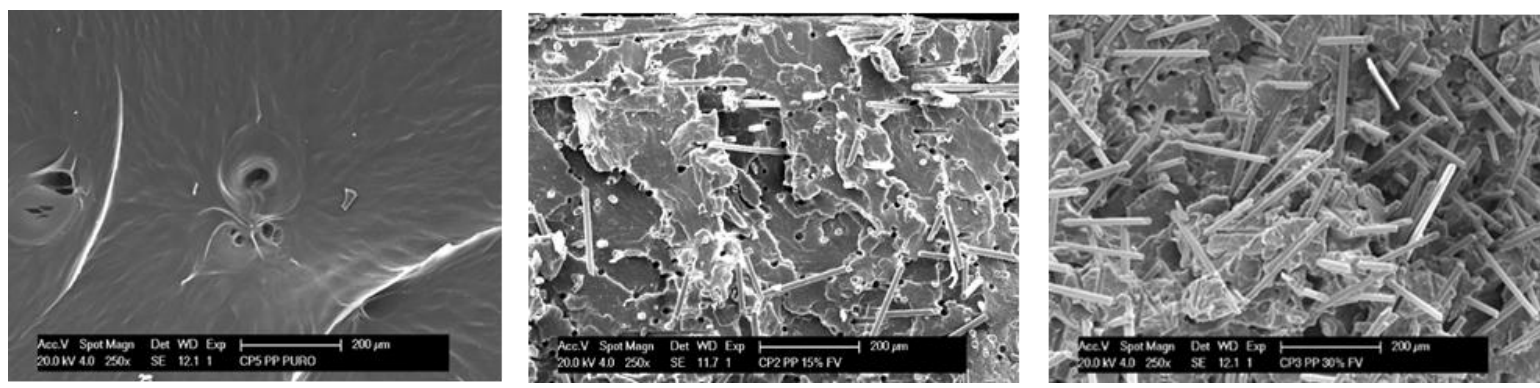

Figura 3: Micrografia da superfície da fratura do CP com aumento de 250 vezes (a) PP puro, (b) PP $15 \%$ e (c) PP $30 \%$.

Na Figura 3(b) e 3(c) podem ser observados vazios provenientes das fibras arrancadas (pull out) e fibras quebradas observadas também em parte do trabalho de [9]. Visualmente percebe-se também uma maior concentração de fibras com o aumento do seu percentual. Com o aumento da concentração de fibra de vidro percebe-se uma redução no percentual de vazios. Vale lembrar outros fatores não explorados neste trabalho que podem alterar este comportamento, ou seja, com o aumento da temperatura de injeção, podem ser observadas tendências similares as que ocorreram com o aumento de concentração de fibras de vidro devido ao fato de ter menos pontas finais de fibras, onde é uma região de concentração de tensão [10]. A temperatura do molde também é um outro fator que pode influenciar o comportamento das fraturas destes compósitos. Uma diminuição na temperatura do molde induz um aumento da tensão de cisalhamento durante o preenchimento do molde e existe uma grande tendência das fibras se orientarem paralelamente para o fluxo de injeção [11]. As injeções dos corpos de prova nesse trabalho foram realizadas sem o aquecimento do molde de injeção.

\subsection{Resultados da injeção e teste prático na carcaça do elemento filtrante.}

A Tabela 3 mostra valores comparativos do processamento do Nylon/30\%FV e do PP/30\%FV para a fabricação da carcaça do elemento filtrante. Os dados apresentados para a injeção do Nylon com $30 \%$ de fibra, já são os usualmente utilizados na fabricação. Já os dados para a injeção do PP, foram inicialmente adotados, aqueles indicados pelo fabricante da matéria prima e foram ajustados durante a injeção das peças. Foram injetadas 30 peças de nylon e 30 peças de PP.

Percebe se que a carcaça do elemento filtrante injetada em PP com 30\% FV apresentou em relação ao Nylon com 30\%FV uma diminuição no consumo de matéria prima da ordem de $15,78 \%$ em peso médio, economia no preço da matéria prima na ordem de $37 \%$, redução da pressão de injeção e ciclo total de injeção de $16,6 \%$ e $36,6 \%$ respectivamente e menores temperaturas nas zonas de aquecimento.

Tabela 3: Valores comparativos do processamento do nylon/30\%FV e do PP/30\%FV

\begin{tabular}{|c|c|c|c|}
\hline & \multicolumn{2}{|c|}{ NYLON/30\% FV } & PP/30\% FV \\
\hline Peso médio da peça & \multirow{4}{*}{\multicolumn{2}{|c|}{$\begin{array}{l}190 \mathrm{~g} \\
\mathrm{R} \$ 13,5 / \mathrm{kg} \\
90 \mathrm{Bar} \\
60 \mathrm{~s}\end{array}$}} & $160 \mathrm{~g}$ \\
\hline Preço de matéria prima & & & $\mathrm{R} \$ 8,40 / \mathrm{kg}$ \\
\hline Pressão de injeção & & & $75 \mathrm{Bar}$ \\
\hline Ciclo total de injeção & & & $38 \mathrm{~s}$ \\
\hline \multirow{5}{*}{$\begin{array}{l}\text { Recomendado pelo fabricante } 230 \text { C a } 190 \text { C temperaturas } \\
\text { nas zonas de aquecimento do canhão }\end{array}$} & $1^{\mathrm{a}}$ & $325^{\circ} \mathrm{C}$ & $210^{\circ} \mathrm{C}$ \\
\hline & $2^{\mathrm{a}}$ & $320^{\circ} \mathrm{C}$ & $200^{\circ} \mathrm{C}$ \\
\hline & $3^{a}$ & $290^{\circ} \mathrm{C}$ & $190^{\circ} \mathrm{C}$ \\
\hline & $4^{a}$ & $280^{\circ} \mathrm{C}$ & $180^{\circ} \mathrm{C}$ \\
\hline & $5^{\mathrm{a}}$ & $270^{\circ} \mathrm{C}$ & $170^{\circ} \mathrm{C}$ \\
\hline
\end{tabular}


O teste prático inicial consistiu da montagem dos discos de apoio e do elemento filtrante na carcaça. Os resultados foram satisfatórios. A Figura 4 (a) mostra a carcaça com os discos de apoio e o elemento filtrante e Figura 4 (b) - Mostra o elemento filtrante sendo montado na carcaça injetada em PP com 30\% de FV.
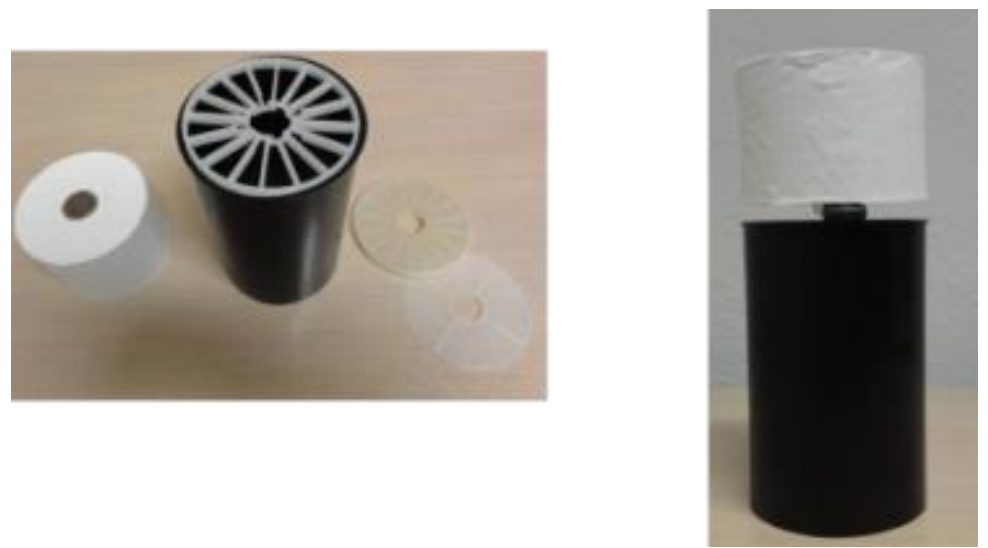

Figura 4: (a) - carcaça com discos de apoio e o elemento filtrante, (b) elemento filtrante sendo montado na carcaça.

Posteriormente ao teste de montagem foram realizados testes de filtragem com aplicação de pressão em bancada durante duas horas e meia. A pressão inicial foi de 5,0 bar e atingiu uma temperatura máxima de $36^{\circ} \mathrm{C}$. Esses valores são similares aos usados quando se utiliza a carcaça confeccionada em Nylon com $30 \%$ de fibra de vidro.

\section{CONCLUSÃO}

O aumento da concentração de fibra de vidro promoveu proporcionalmente uma diminuição na contração da amostra do compósito em função da resistência que a fibra de vidro proporcionou pela sua menor plasticidade.

A resistência à tração aumenta com o aumento da quantidade de carga de fibra. Já o alongamento na tração, diminui. Através das imagens de microscopia observou-se que a adesão entre a fibra de vidro e a matriz polimérica não ocorreu completamente, mesmo com a utilização de um agente de adesão recomendado pelo fornecedor da matéria prima. Quando se observa as imagens de MEV são visíveis alguns pontos de "pull-out" e a falta de indícios de matriz aderida nas fibras arrancadas.

O esforço de flexão máximo e o módulo de elasticidade (Young) aumentaram com o aumento da quantidade de carga de fibra de vidro no compósito. A inclusão das fibras de vidro foi responsável também por um aumento significativo da resistência ao impacto $(19,23 \mathrm{~J} / \mathrm{m}-15 \% \mathrm{FV} \Rightarrow 58,77 \mathrm{~J} / \mathrm{m}-30 \% \mathrm{FV})$ que aumenta com o aumento do teor de fibra de vidro. Na análise termogravimétrica, a concentração de fibras foi confirmada em concordância com os valores apresentados pelo fornecedor da matéria prima.

A injeção da carcaça do elemento filtrante utilizando polipropileno com 30\%/FV, apresentou resultados positivos tanto na montagem dos discos de apoio e elemento filtrante quanto nos testes de bancada efetuados. Considerando os valores comparativos do processamento do nylon/30\%FV e do PP/30\%FV (Tabela 3), visualiza se uma redução de custos geral entre $18 \%$ a $22 \%$ com a substituição do nylon pelo polipropileno na fabricação da carcaça. Apresenta se ainda a vantagem da utilização de polipropileno de fabricação nacional em comparação com nylon (poliamida), que é importada.

\section{AGRADECIMENTOS}

Os autores agradecem á PUC-MG - Pontifícia Universidade Católica de Minas Gerais e a FCA - Fiat Chrysler Automobites pelo suporte dado neste estudo.

\section{BIBLIOGRAFIA}

[1] HEMAIS, C. A.. "Polímeros e a indústria automobilística", Polímeros, v. 13, n. 2, 107-114pp. June 2003.

[2] MOL, A.S. Preparação e funcionalização de nano fibras (Whiskers) de quitina e sua aplicação como agente de recuperação de propriedades em polipropileno e poli (acrilonitrila-butadieno-estireno) reciclados, 
Tese de D.Sc, Programa de Pós-Graduação de Engenharia Metalúrgica, Materiais e de Minas, Universidade Federal de Minas Gerais, Belo Horizonte, MG, Brasil, 2014.

[3] PIZZITOLA, I. C. P., MACHADO, M. M., WIEBECK, H. "Propriedades mecânicas e comportamento a emissões de voláteis de compósitos de polipropileno/fibras curtas de sílica", Polímeros [online]. v.21, n.3, pp.223-228, 2011.

[4] YOUSSEF, A. H., MADHURANTHAKAM, C., MOULI, R., et al., "Optimizing mechanical propertirs of injection-molded long fiber-reiforced polypropylene", Journal of Thermoplastic Composite Materials. v. 28, n. 6, 849-862, pp. April 2015.

[5] XIAODONG, L., BOLDIZAR, A., RIGDAHL, M., et al., "Recycling of blends of acrylonitrilebutadiene-styrene (ABS) and polyamide", Journal of Applied Polymer Science, v. 86, n. 10, pp. 2535-2543, Sep. 2002.

[6] ASTM D638-14, Standard Test Method for Tensile Properties of Plastics, ASTM International, West Conshohocken, PA, 2014.

[7] ASTM D790-17, Standard Test Methods for Flexural Properties of Unreinforced and Reinforced Plastics and Electrical Insulating Materials, ASTM International, West Conshohocken, PA, 2017.

[8] ASTM D256-10e1, Standard Test Methods for Determining the Izod Pendulum Impact Resistance of Plastics, ASTM International, West Conshohocken, PA, 2010.

[9] LOPES, P. E., SOUSA, J. A. "Influência das condições de processamento nas propriedades mecânicas de compósitos de polipropileno com fibras de vidro", Polímeros [online]. 1999, v.9, n.1, pp.85-96. ISSN 01041428.

[10] OTA, W.N. Análise de compósitos de polipropileno e fibras de vidro utilizados pela indústria automotiva nacional. Dissertação de M.Sc., Programa Interdisciplinar de Pós-Graduação em Engenharia, Universidade Federal do Paraná, PR, Brasil, 2004.

[11] FU, S.-Y., et al., "Hybrid effects on tensile properties of hybrid short-glass-fiber-and short-carbon-fiberreinforced polypropylene composites ", Journal of Materials Science, v. 36, n. 5, 1243-1251pp. March 2001.

[12] FEJES-KOZMA Z., KARGER-KOCSIS J. "Fracture mechanical characterization of a glass-fiber material reinforced polypropylene by instrumented impact bending", Journal of Reinforced Plastics and Composites, v. 13, n. 9, 822-834pp. Sep. 1994.

[13] GUPTA, A.K. SRINIVASAN, K.R., KUMAR, P.K. "Glass-Fiber reinforced Polypropylene EPDM blends. II. Mechanical properties and morphology", Journal of Applied Polymer Science, v. 43, n. 3, 451462pp. Aug.1991.

[14] THOMASON J.L. VLUG, M.A. "Influence of a fibre length and concentration on the properties of glass fibre-reinforced polypropylene .IV. Impact properties, composites, Part A", Applied Science and Manufacturing, v. 28, n. 3, 277-288pp. 1997.

[15] CHIU, W.Y. LU, H.C, CHANG, C.L. "Relationship between extrusion condition and mechanical properties of FRPP”, Journal of Applied Polymer Science, v. 43, n. 7, 1335-1341pp. Oct. 1991.

\section{ORCID}

Gilmar Cordeiro da Silva

Geraldo Flávio Ximenes Ladeira

José Rubens Gonçalves Carneiro

Hermano Nascimento Júnior https://orcid.org/0000-0002-5405-8086

https://orcid.org/0000-0002-6444-7392

https://orcid.org/0000-0001-7937-6083

https://orcid.org/0000-0001-5191-6586 